\title{
Temporal Evolution of the Gravitaxis of Euglena gracilis from a Single Cell
}

\author{
Kazunari Ozasa ${ }^{1,2, *(\mathbb{D})}$, Hyunwoong Kang ${ }^{3} \mathbb{D}$, Simon Song ${ }^{3,4}$, Shota Kato ${ }^{5}\left(\mathbb{D}\right.$, Tomoko Shinomura ${ }^{6}(\mathbb{D}$ \\ and Mizuo Maeda 1,7
}

Citation: Ozasa, K.; Kang, H.; Song, S.; Kato, S.; Shinomura, T.; Maeda, M. Temporal Evolution of the Gravitaxis of Euglena gracilis from a Single Cell. Plants 2021, 10, 1411. https:// doi.org/10.3390/plants10071411

Academic Editor: Antonino Pollio

Received: 4 June 2021

Accepted: 4 July 2021

Published: 9 July 2021

Publisher's Note: MDPI stays neutral with regard to jurisdictional claims in published maps and institutional affiliations.

Copyright: (c) 2021 by the authors. Licensee MDPI, Basel, Switzerland. This article is an open access article distributed under the terms and conditions of the Creative Commons Attribution (CC BY) license (https:// creativecommons.org/licenses/by/ $4.0 /)$.
1 Bioengineering Laboratory, Cluster for Pioneering Research, RIKEN, 2-1 Hirosawa, Wako, Saitama 351-0198, Japan; mizuo@riken.jp

2 Advanced Laser Processing Research Team, RIKEN Center for Advanced Photonics, RIKEN, 2-1 Hirosawa, Wako, Saitama 351-0198, Japan

3 Department of Mechanical Engineering, Hanyang University, 222 Wangsimni-ro, Seongdong-gu, Seoul 04763, Korea; kang1026@hanyang.ac.kr (H.K.); simonsong@hanyang.ac.kr (S.S.)

4 Institute of Nano Science and Technology, Hanyang University, 222 Wangsimni-ro, Seongdong-gu, Seoul 04763, Korea

5 Center for Bioscience Research and Education, Utsunomiya University, Mine 350, Utsunomiya, Tochigi 321-8505, Japan; shota.kato.680@gmail.com

6 Plant Molecular and Cellular Biology Laboratory, Department of Biosciences, School of Science and Engineering, Teikyo University, 1-1 Toyosatodai, Utsunomiya, Tochigi 320-8551, Japan;

shinomura@nasu.bio.teikyo-u.ac.jp

7 Liver Cancer Prevention Research Unit, Cluster for Pioneering Research, RIKEN, 2-1 Hirosawa, Wako, Saitama 351-01, Japan

* Correspondence: ozasa@riken.jp; Tel.: +81-48-462-1111 (ext. 8544); Fax: +81-48-462-4682

Abstract: Gravitaxis is one of the most important issues in the growth of microalgae in the water column; it determines how easily cells receive sunlight with a comfortable intensity that is below the damaging threshold. We quantitatively investigated and analyzed the gravitaxis and cell multiplication of Euglena gracilis using vertically placed microchambers containing a single cell. A temporal change in gravitaxis and cell multiplication was observed after transferring the cells to fresh culture medium for 9 days. We performed 29 individual experiments with $2.5 \mathrm{~mm} \times 2.5 \mathrm{~mm} \times 0.1 \mathrm{~mm}$ square microchambers and found that the cells showed positive, negative, and moderate gravitaxis in 8,7 , and 14 cases, respectively, after transferring to fresh culture medium. A common trend was observed for the temporal change in gravitaxis for the eight initially positive gravitaxis cases. The cells with initially positive gravitaxis showed a higher rate of cell multiplication than those with initially negative gravitaxis. We also discussed the gravitaxis mechanism of E. gracilis from the observed trend of gravitaxis change and swimming traces. In addition, bioconvection in a larger and thicker chamber was investigated at a millimeter scale and visualized.

Keywords: positive gravitaxis; microfluidic devices; cell metabolism; swimming traces; bioconvection

\section{Introduction}

Gravitaxis is a fundamental characteristic of both land and sea plants. Even in the absence of light, gravity indicates the direction in which plants should grow to obtain sunlight. A plant seed lying in soil can respond to gravity to determine the direction to extend its roots and shoots. Several motile microalgae in water also exhibit negative gravitaxis and gather near the surface area of the water column to catch sunlight [1-3]. Microalgae swimming in water may find it difficult to detect gravity, because buoyancy and water flow disturb gravity sensing [3]. For microalgae in water, one of the simplest ways to swim toward or against gravity is to use buoyancy, i.e., rising to the surface of the water column and sinking to the bottom by buoyancy-affected heading mechanisms [4,5]. In such cases of passive gravitaxis, a microalgal cell must change its center of mass from 
the anterior region to the stern region, or vice versa, to produce positive or negative gravitaxis $[6,7]$. The other approach to exhibit gravitaxis is for algae to detect the direction of gravity and swim upward/downward using its own propelling force. In this case, the microalgae can determine the sign of gravitaxis as per its age or growth stage, as well as from the environmental conditions, including nutrients and light. Hence, the gravitaxis of microalgae is a key factor in the industrial application of microalgae for green chemistry $[8,9]$. In addition, the phenomenon is important for the fishery and water leisure industries because natural microalgae blooms have a significant impact on sea and lake ecosystems [10,11].

Gravitaxis of unicellular microalgae has been extensively investigated, especially for Chlamydomonas reinhardtii and Euglena gracilis, both of which are eukaryotes with photosynthesizing chloroplasts and propelling devices. C. reinhardtii is a model organism for unicellular microalgal studies, possessing two anterior flagella and multiplying with both asexual and sexual reproduction. E. gracilis is also a model organism, possessing an emergent flagellum and multiplying only with asexual reproduction, i.e., cell division. E. gracilis is more preferable than $C$. reinhardtii for the investigation of the succession of characteristics such as gravitaxis and phototaxis, since no crossover and mixing of genotypes is involved in asexual reproduction of E. gracilis. Cellular structures of E. gracilis can be found in previous literatures with detailed microphotographs and electron micrographs $[12,13]$.

We aimed to understand the way in which E. gracilis gravitaxis changes according to cell growth, multiplication, and chemical changes in a culture medium, as well as environmental changes in a water column. Previous studies [14,15] indicated that E. gracilis gravitaxis changes with cell culture conditions. Cells in a young culture exhibited positive gravitaxis, whereas those in an aged culture exhibited negative gravitaxis. We were also interested in the behavior and mechanism of gravitaxis, including the ways in which a cell changes its swimming direction with respect to gravity [16].

In this paper, we report the gravitactic behavior of a single E. gracilis cell and its temporal changes with cell multiplication. We examined three types of a micrometer scale water column chamber: a square microchamber to observe the entire area in situ, a rectangular microchamber to observe the top and bottom areas separately, and a mini test tube chamber to observe convection at the surface and bottom areas separately. Temporal changes in gravitaxis along with cell multiplication were measured from a single cell up to several hundreds of cells within 9 days. Results revealed that the gravitaxis of E. gracilis after being transferred to fresh culture medium was positive in ca. $28 \%$ of cases, negative in ca. $24 \%$, and moderate in ca. $48 \%$; however, all cases showed negative gravitaxis after 4 days of cell culture. In addition, we tracked the gravitactic motion of E. gracilis and discuss the mechanism of the gravitaxis of E. gracilis compared with its phototactic motion. Finally, the occurrence of bioconvection was investigated and visualized in a larger chamber at a millimeter scale.

\section{Materials and Methods}

E. gracilis $\mathrm{Z}$ strain cells were used in this study. The cells were cultured in CM medium [17] with the addition of $0.1 \%$ ethanol to assist cell growth via heterotrophical nutrition supply. The cells were maintained at the growth saturation level under moderate room light and room temperature $\left(23^{\circ} \mathrm{C}-26^{\circ} \mathrm{C}\right)$ without air bubbling. The cell suspension was refreshed by successive cultures every two weeks. Approximately $2 \mathrm{~h}$ prior to starting the experiments, the cell suspension was diluted with fresh $\mathrm{CM}$ medium with $0.1 \%$ ethanol to a concentration of ca. 1000-5000 cells $/ \mathrm{mL}$. The $\mathrm{pH}$ value of the 2-week-old cell suspension was 4.62, whereas that of the fresh CM medium was 5.95. Therefore, the transfer to the fresh medium represented chemical environmental changes for the cells.

We used three types of water column microchambers named A, B, and C. Type A was a square microchamber that was $2.5 \mathrm{~mm}$ in height (gravity direction) $\times 2.5 \mathrm{~mm}$ in width $\times 100 \mu \mathrm{m}$ in thickness. Type B was a rectangular microchamber that was $20 \mathrm{~mm}$ in height $\times 2.5 \mathrm{~mm}$ in width $\times 100 \mu \mathrm{m}$ in thickness. Type $C$ was a mini test tube chamber 
that was $20 \mathrm{~mm}$ in height $\times 8 \mathrm{~mm}$ in width $\times 1.6 \mathrm{~mm}$ in thickness. The liquid holding capacity of type A, B, and C microchambers was $0.625,5.0$, and $256 \mu \mathrm{L}$, respectively. All areas of the type A microchamber were observed in situ in a single frame of our optical microscope, whereas only the top and bottom areas were separately observed for types $B$ and $C$ microchambers. Types $A$ and $B$ microchambers were made up of polydimethylsiloxane (PDMS) and covered with a glass coverslip after placing a droplet of E. gracilis cell suspension on the microchamber. The cell concentration of the suspension was low enough that only a single cell could be confined in the type A and B microchambers after a couple of trials. The type $\mathrm{C}$ chamber was an acrylic cell with an open top. For experiments using the type $\mathrm{C}$ chamber, the chamber was first filled with fresh $\mathrm{CM}$ medium with $0.1 \%$ ethanol and, subsequently, $10 \mu \mathrm{L}$ cell suspension was added to the medium; this resulted in ca. 100-500 cells in the chamber. Figure 1 shows the outlook of each microchamber.

(a)
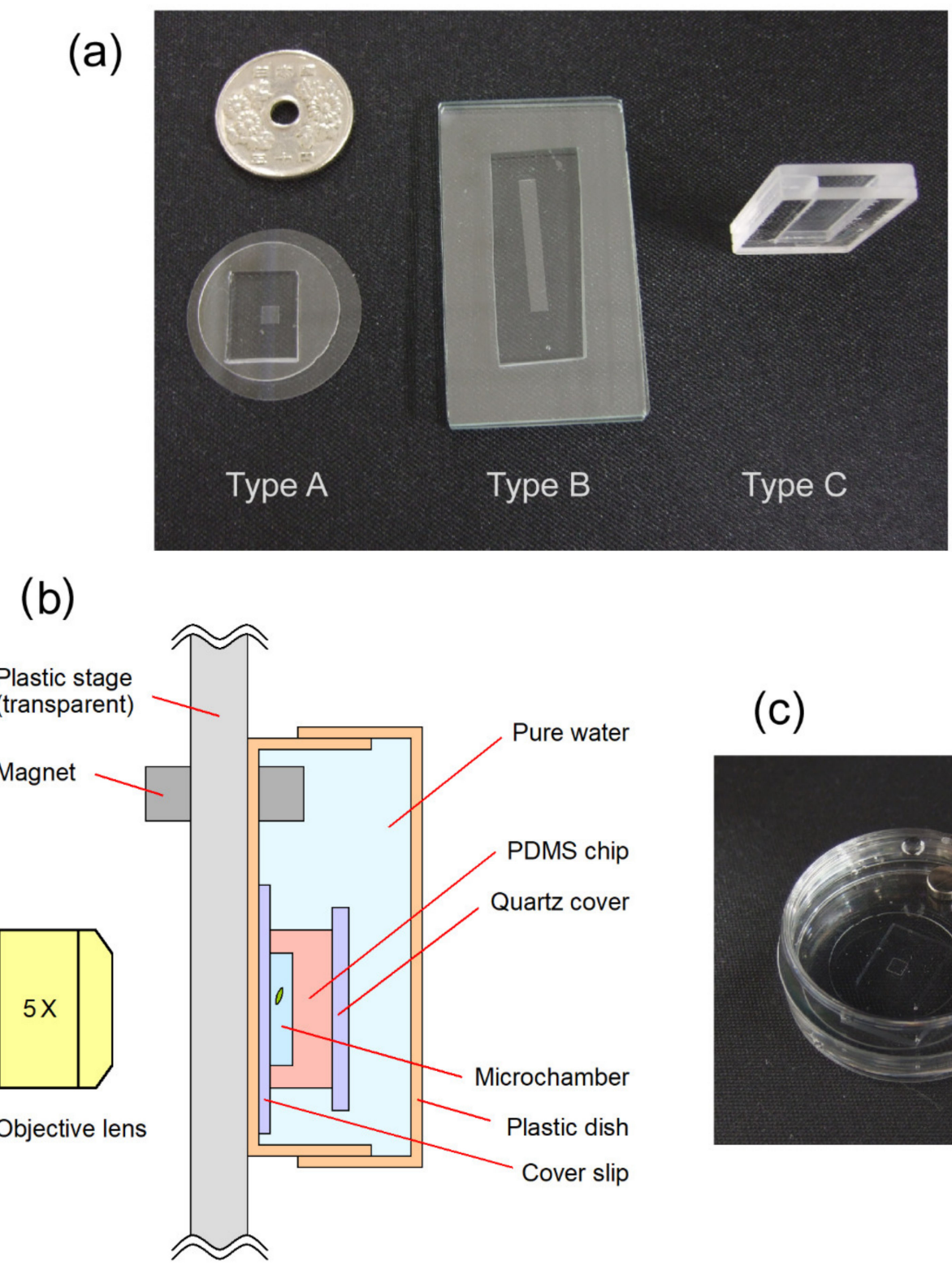

(c)

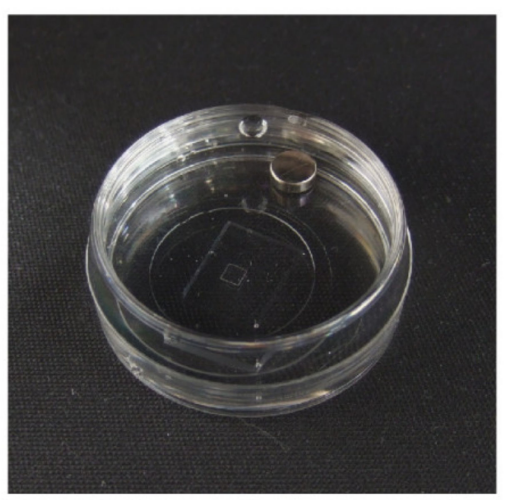

Figure 1. (a) Three types of microchamber used in this study. (b) Configuration of gravitaxis observation with the type A microchamber. Type A and B microchambers were contained in a plastic dish filled with pure water to prevent the microchamber from drying. (c) Photograph of the type A microchamber contained in a plastic dish filled with pure water, corresponding to the illustration (b). 
We conducted 29, 5, and 6 experiments with type A, B, and C microchambers, respectively. Three to seven experiments with individual type A microchambers were undertaken simultaneously, six times in total. The experiments with type B and C microchambers were performed one by one. The cells for the experiments were taken from the two-week-old cell suspension and transferred to a fresh CM medium with $0.1 \%$ ethanol to maintain the initial cell condition of each experiment as closely as possible. A vertical microscope with a 5X objective lens (MPlanFLN 5X/0.15, Olympus, Tokyo, Japan) was used to observe the vertically placed microchambers [18]. The experiments were performed under room illumination at room temperature, and infrared illumination was used for microscopic observation. As we previously reported [19,20], cell movement was tracked using video image processing technology developed in-house. The images were $800 \times 600$ pixels, with a resolution of $2500 \mu \mathrm{m} / 512$ pixels, and refreshed at a frame rate of ca. $12.7 \mathrm{~s} /$ frame. The swimming traces in each image were counted using pixels and named "trace momentum $(\mathrm{TM})$ " to represent the total swimming activity of the cells within the observation area. For type A experiments, the center of gravity of swimming traces $\left(\mathrm{X}_{\mathrm{c}}, \mathrm{Y}_{\mathrm{c}}\right)$ was calculated to estimate the gravitaxis of the cells. For the larger microchambers of types B and C, only the top and bottom areas were separately observed.

\section{Results}

\subsection{Temporal Evolution of Cell Multiplication and Gravitaxis}

Figure 2 shows an example of the temporal evolution of the center of cell distribution $\left(X_{c}, Y_{c}\right)$, swimming activity evaluated as a TM value, and cell number estimated by our algorithm previously reported [21]. The detail of the initial stage of Figure 2 is presented as an expanded plot in Supplementary Figure S1. Trace images are shown in Figure 3 for the representative timings indicated in Figure 2. The center of the microchamber corresponds to $\left(X_{c}, Y_{c}\right)=(0.0,0.0)$, whereas the top and bottom edges correspond to $Y_{c}=256$ and -256 , respectively.

At the early stage (day $0.0-0.06,0.0-1.4 \mathrm{~h}$ ) of cell culture in the type A microchamber, the Yc value was negative and ranged from -180 to -150 . This indicates that the cell stayed within $520 \mu \mathrm{m}$ of the bottom edge of the microchamber, an area in the lowest quarter of the water column. The swimming traces presented in Figure 3a showed that the cell exhibited positive gravitaxis, with a circular swimming trace toward the bottom of the microchamber. The positive gravitaxis of the cell was gradually weakened up to $\mathrm{Yc}_{\mathrm{c}}=-35$ for $1.0-7.4 \mathrm{~h}$ (day 0.04-0.31). The TM value remained nearly constant in this period, indicating that the swimming speed of the cell did not significantly change. The swimming trace of the cell gradually changed from circular to straight swimming.

The first cell division occurred at $7.7 \mathrm{~h}$ (day 0.32) (Figure 2 and Figure S1), where the decrease in the TM value showed that the cell ceased swimming. At cell division, the flagellum of E. gracilis is degraded to zero length and the cell usually sinks to the bottom of the water column [12,22-24]. The cell in Figure 3a also sank down and divided into two daughter cells. Because the cell did not move during cell division, the TM value dropped to zero, and the $Y_{c}$ and $X_{c}$ values became unreliable because of the lack of trace images of the cell. Two new daughter cells started swimming at $10.6 \mathrm{~h}$ (day 0.44) and initially showed almost no gravitaxis (Yc was close to zero). After $30 \mathrm{~min}$, a shift to positive gravitaxis occurred, and Yc became nearly -120 at $14 \mathrm{~h}$ (day 0.58). After $14 \mathrm{~h}$ (day 0.6), gravitaxis gradually shifted to negative from $Y_{c}=-120$ to zero at $18.5 \mathrm{~h}$ (day 0.77 ) and the cells swam without directional preferences (Figure 3b). After the second cell division at 20.0-22.6 h (day 0.83-0.94), the gravitaxis of four cells became strongly negative (Yc was close to 130) and the cells stayed in the uppermost third area (Figure 3c). After the third cell division at day 1.35-1.43, seven or eight cells swam in a larger area (Figure 3d) than observed previously (Figure 3c), indicating that a diversity of cell characteristics emerged. However, Yc remained close to 130, indicating strongly negative gravitaxis. 


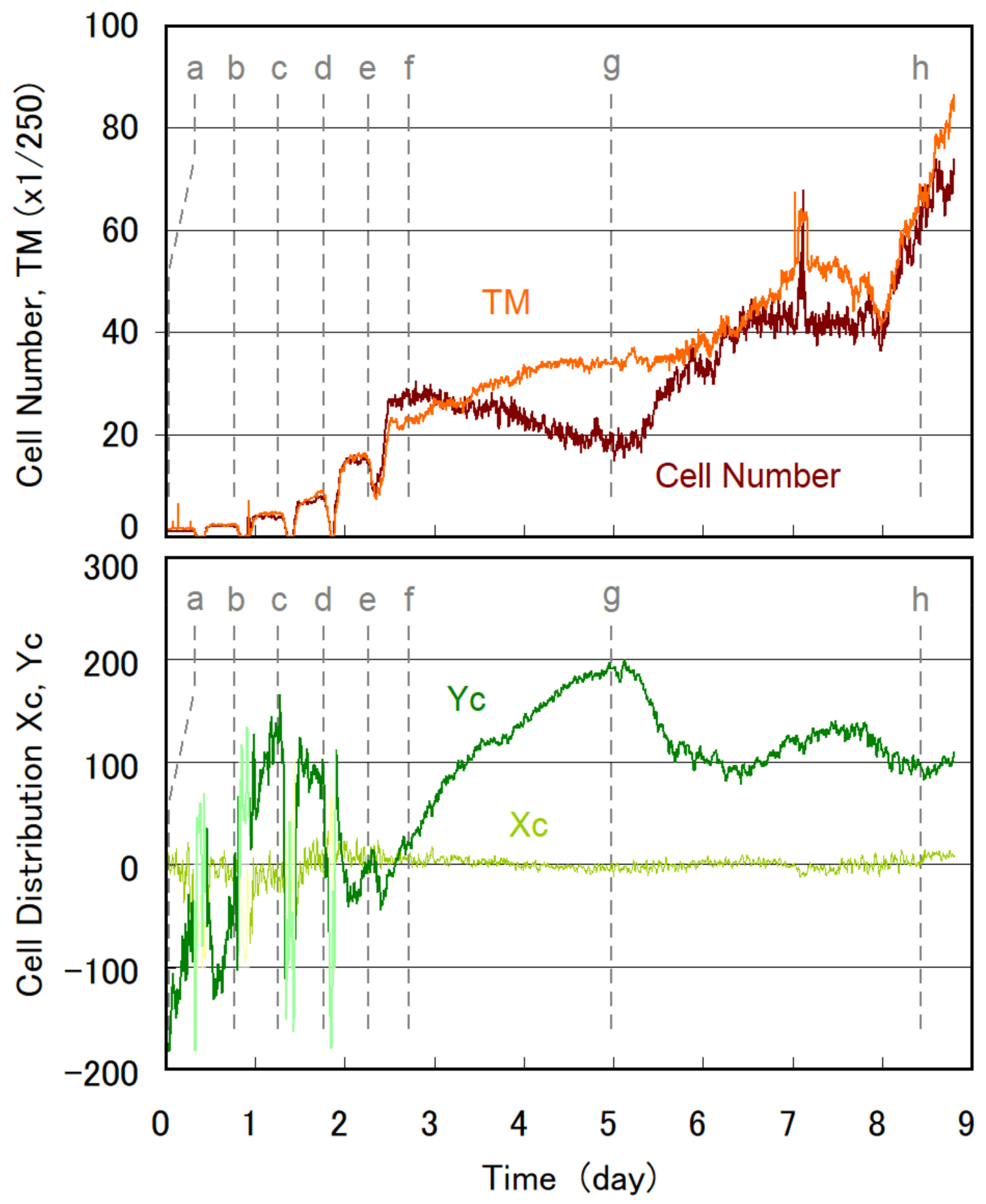

Figure 2. Temporal change in the center of cell distribution $\left(\mathrm{X}_{\mathrm{c}}, \mathrm{Y}_{\mathrm{c}}\right)$, swimming activity evaluated as a TM value, and cell numbers estimated by our analyzing algorithm. Cell distribution ( $\left.X_{c}, Y_{c}\right)$ was not valid for the periods of no TM value and is therefore faded in the figure. Irregular notches were due to some artifacts, such as noise and unintentional microchamber movements. The early stage of day 0.0-2.2 is presented in Figure S1. 

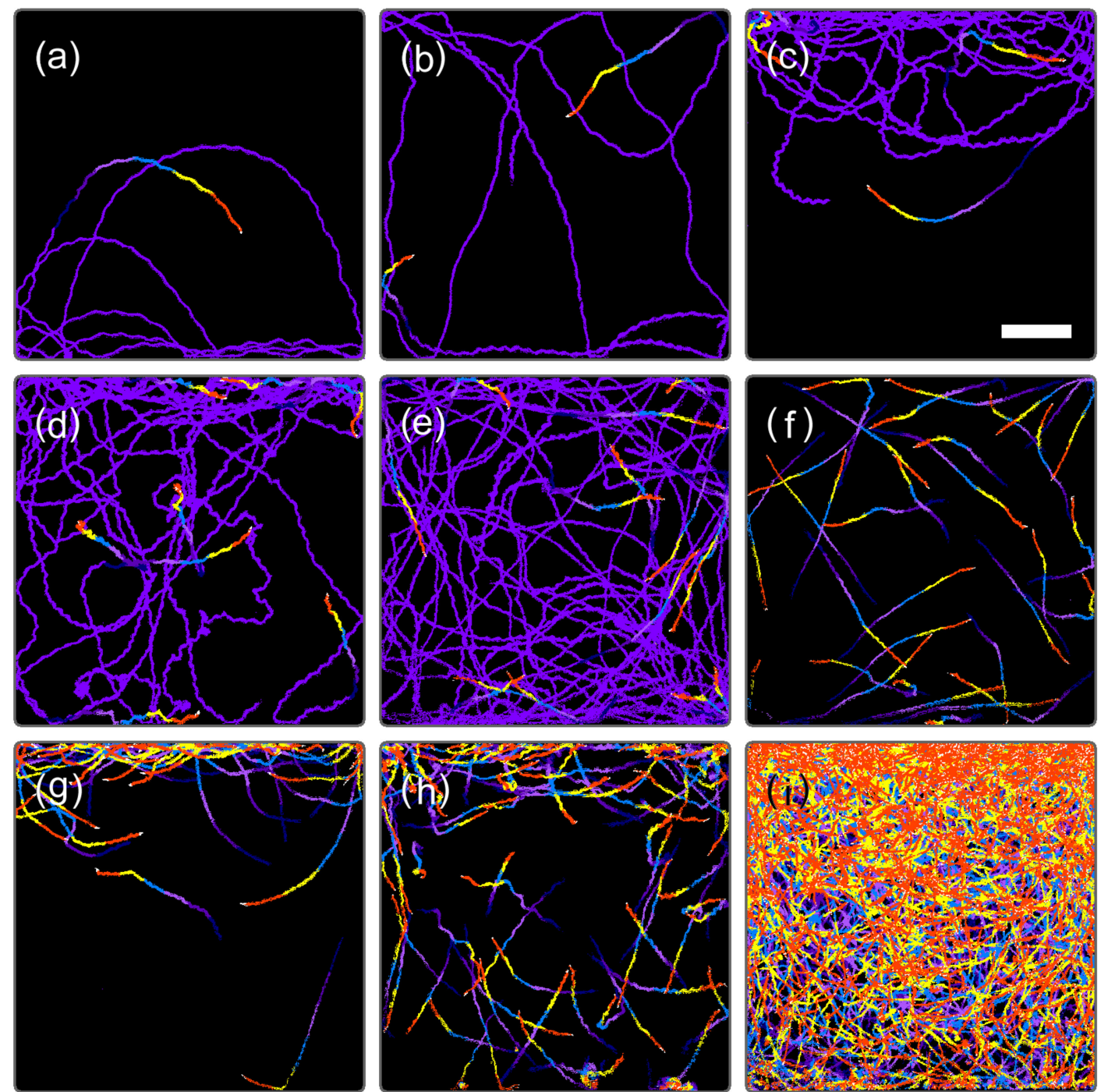

Figure 3. Trace image observed at day (a) 0.01, (b) 0.77, (c) 1.26, (d) 1.76, (e) 2.26, (f) 2.72, (g) 4.97, (h) 8.44, and (i) 13.97, corresponding to the timings indicated in Figure 2. Traces for 149.2 and $12.4 \mathrm{~s}$ were superimposed for $(\mathbf{a}-\mathbf{e})$ and (f-i), respectively. In the images of $(\mathbf{a}-\mathbf{i})$, traces obtained for the last $12.4 \mathrm{~s}$ ( 6 frames $\times 2.07 \mathrm{~s} /$ frame) were superimposed with different colors for visualization purposes. Scale bar in (c) indicates $0.5 \mathrm{~mm}$.

As the cell number increased to 16-30 for day 2.0-3.0, the Yc value returned to almost zero and swimming traces were distributed almost uniformly in the microchamber (Figure 3e,f). Subsequently, Yc gradually increased to ca. 200, indicating a highly negative gravitaxis with swimming traces remaining at the upper part of the microchamber (Figure 3g). Eventually, Yc settled at 70-130 after day 6.0, where some cells stayed in the upper part and some cells swam down to the bottom; however, they still showed circular swimming towards the top (Figure $3 \mathrm{~h}$ ).

The cell number estimated by our algorithm corresponded well with the TM value, indicating that the value represents the progress of cell multiplication. The deviations observed at day 4.0-5.6 were due to the underestimation of cell numbers owing to the overlap of swimming traces in trace images. Neither the cell number nor the TM value showed an ideal exponential growth, stagnating at day 3.0-8.0. The reason for the stagnant period is unclear.

\subsection{Trends of Gravitaxis and Cell Multiplication}

We performed 29 experiments with type A microchambers and found diversity in gravitaxis while focusing on the initial stage of cell multiplication. The histogram of "initial 
$\mathrm{Yc}_{\mathrm{c}}$ " and "Yc at day 8.5 " is shown in Figure 4a. We categorized 29 experiments according to initial $Y_{c}$ as positive $\left(Y_{c}<-90\right)$, negative $\left(Y_{c}>90\right)$, or moderate $\left(-90<Y_{c}<90\right)$ for initial gravitaxis. The categorization resulted in 8 positive, 7 negative, and 14 moderate initial gravitaxis. Approximately $30 \%$ of the E. gracilis cells that were transferred to fresh $\mathrm{CM}$ medium exhibited positive gravitaxis.
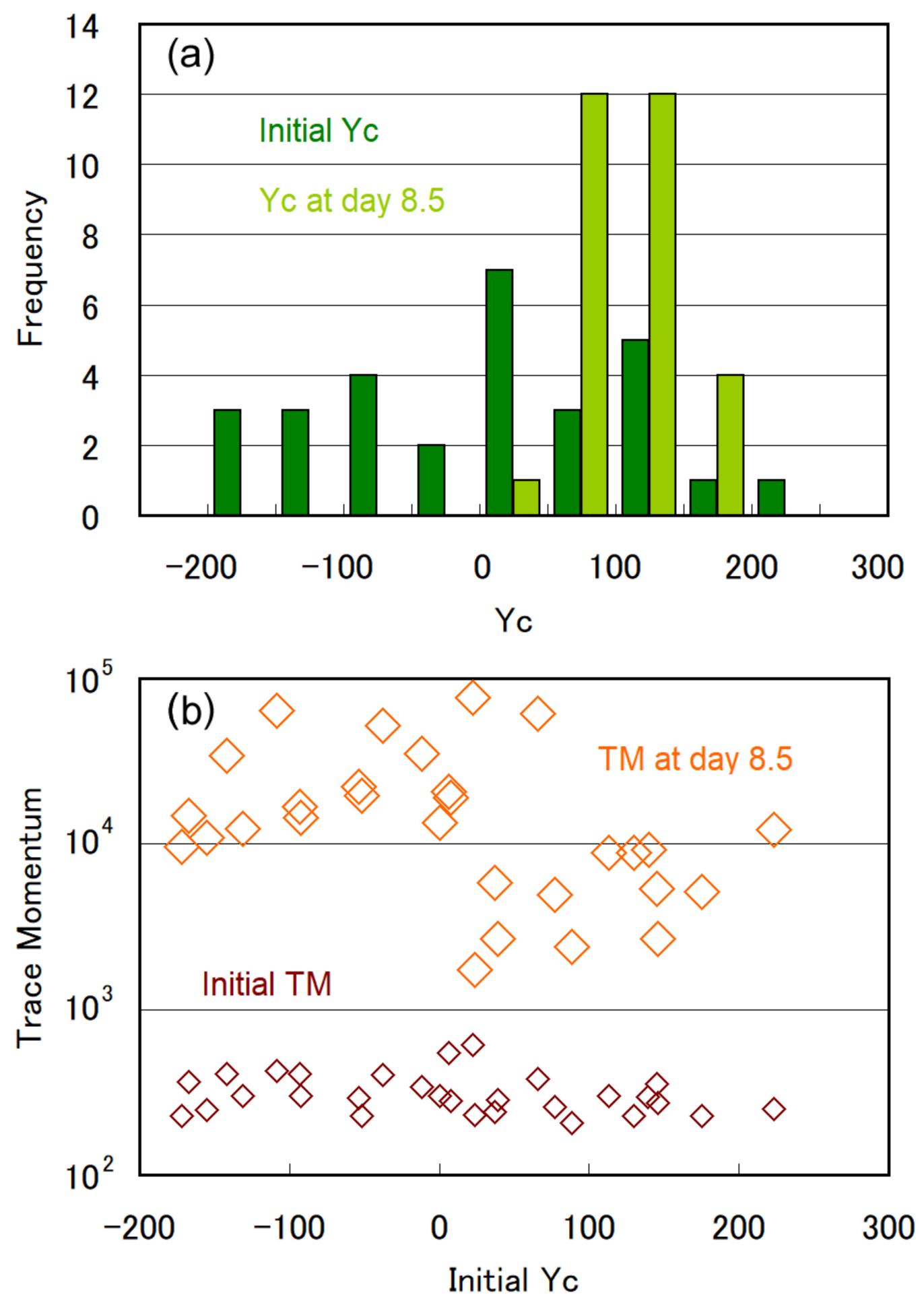

Figure 4. (a) Histogram of initial $Y_{c}$ and $Y_{c}$ at day 8.5, binned in 50 pixels. (b) Relation between initial $Y_{c}$ and trace momentum (initial TM and TM at day 8.5). 
The temporal change in the Yc and TM values are plotted in Figure 5a,b for 8 positive and 7 negative cases. The same plot for 14 moderate cases is presented in Supplementary Figure S2. Although the plots show a natural deviation and scattering owing to the diversity in cell characteristics, interesting trends can be deduced from the data shown in Figure 5a. For the initially positive cases in Figure $5 \mathrm{a}$, the gravitaxis became negative when the cell number increased from four to eight and subsequently became moderate at day $2-3$. The cells showed negative gravitaxis again after day 4, and Yc eventually converged to a range of $100 \pm 50$. Of note, this trend was observed for all eight initially positive cases (Figure 5a). This observation showed that the changes in gravitaxis were mostly synchronized after the transfer of the cells to fresh CM medium. The temporal change in Yc did not show specific trends for the initially negative cases shown in Figure 5 b nor the initially moderate cases shown in Figure S2, except that Yc converged in the range of $100 \pm 80$. The convergence of Yc with cell multiplication can be clearly observed in Figure $4 \mathrm{a}$ in the histogram of Yc at day 8.5 .

The rate of cell multiplication observed in the experiments was also diverse, as per the TM growth (Figure 5a,b and Figure S2). Some cases showed an ideal exponential growth, including cases 6,18 , and 29, whereas some were nearly saturated, such as 11 and 16. However, we found a significant relationship between the cell multiplication rate and initial gravitaxis in the plot of TM value versus initial Yc (Figure 4b). Although the initial $\mathrm{TM}$ values at the early stage of cell culture were almost independent of the initial $\mathrm{Yc}_{\mathrm{c}}$, the $\mathrm{TM}$ values at day 8.5were higher for the cases with $\mathrm{Y}_{\mathrm{c}}<0$ (positive gravitaxis) than for those with $\mathrm{Yc}_{\mathrm{c}}>0$ (negative gravitaxis).

\subsection{Specific Observation for Top and Bottom Area}

Figure 6 shows trace images obtained from the type B experiment for the top and bottom areas of the type B microchamber. The initial single cell in Figure 6 exhibited positive gravitaxis at the early stage of cell multiplication (Figure 6a) at day 0.04. After the first cell division, one of the two cells exhibited negative gravitaxis at day 0.78 (Figure 6b), whereas another cell stayed at the bottom for cell division (not shown). This trend in gravitaxis change was the same as that observed in the type A microchamber for the cells with initially positive gravitaxis (Figure 5a). At a later stage of cell multiplication, at day 8.32, most of the cells exhibited negative gravitaxis (Figure 6d), whereas some showed positive gravitaxis at the bottom (Figure 6c). The band-like and circular traces evident in Figure $6 \mathrm{c}$ were due to the irregular movements of mitotic cells at the later stages of cell cleavage. As cell multiplication proceeded, the number of cells at the top area of the type B microchamber increased (Figure 6f), whereas an accumulation of immobile cells was observed at the bottom (Figure 6e). The immobile cells could not be detected by swimming traces (Figure 3i) but gradually accumulated and formed a stagnant layer at the bottom of the microchambers.

When the water column became larger and thicker in the type $C$ chamber, a convectional flow was detected in the swimming traces. At the early stage of cell multiplication in the type $C$ chamber (Figure 7a,b), observed swimming traces were randomly oriented, as is usual for E. gracilis in still water in a microchamber. However, the collective movements of the cells were observed after a couple of days as traces with the same direction at the surface (Figure 7c) and at the bottom (Figure 7d). Real-time cell movements are presented as Supplementary Movie S3 and S4 for the surface and bottom, respectively. The collective movements were due to convectional flow in which the cells were captured and flowed. The convection was not observed when the cell density was small, indicating that the convection was not thermal but was due to bioconvection [25-27]. Large numbers of cells gathering at the surface by negative gravitaxis produce a dense region. Because E. gracilis cells are denser than the CM medium [18], gyrotactic instability occurs. The dense region then starts to sink downward (Figure 7c, right side), drawing more cells into the region. The downward flow of dense cells reaches the bottom and can be observed as a dense column of cells (Figure 7d, right side). A large number of cells were brought to the bottom 
by bioconvection, resulting in the reversal of the cell population at the surface and bottom; the cells exhibited negative gravitaxis, but the cell population was denser at the bottom than at the surface.

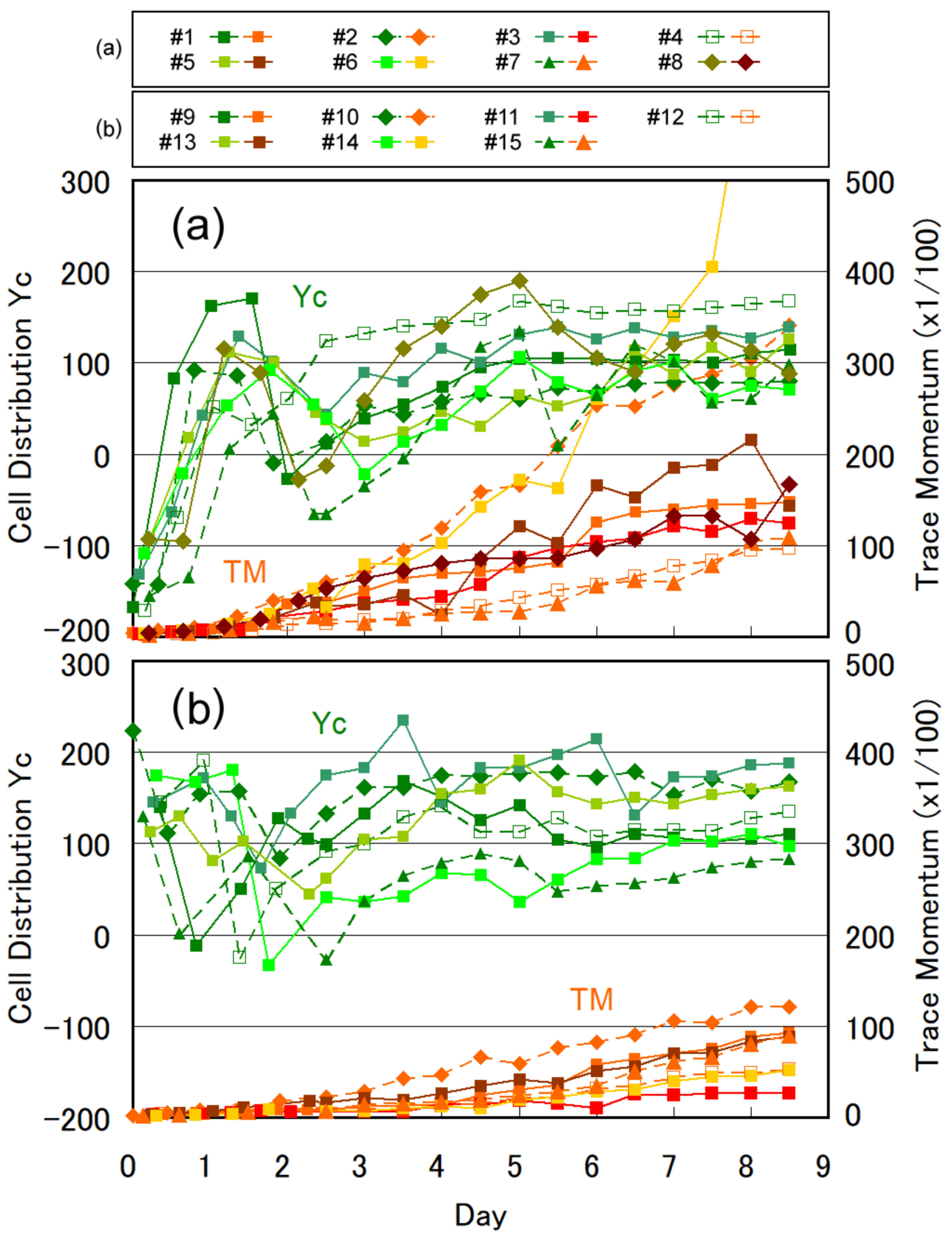

Figure 5. Temporal change in the center of cell distribution Yc and swimming activity evaluated as a TM value for (a) 8 cases of initially positive gravitaxis and (b) 7 cases of initially negative gravitaxis. See Supplementary Figure S2 for 14 cases of initially moderate gravitaxis. Case 8 in Figure 4a corresponds to Figure 2. 

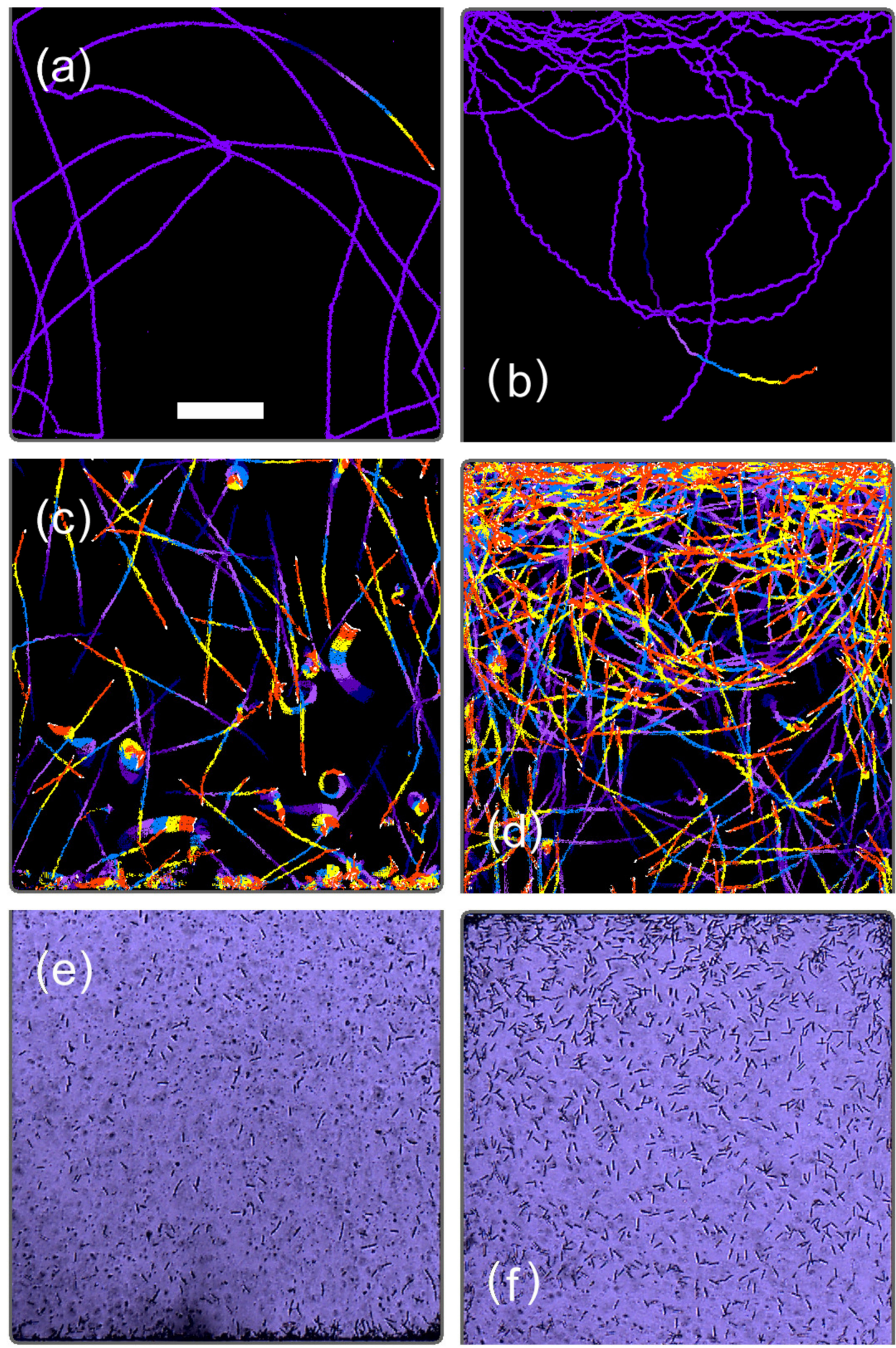

Figure 6. Trace images (a-d) showing cellular movements and a real image (e,f) of E. gracilis observed for type B experiment. $(\mathbf{a}, \mathbf{c}, \mathbf{e})$ Bottom area, (b,d,f) top area at (a) $0.96 \mathrm{~h}$ (day 0.04), (b) $18.7 \mathrm{~h}$ (day 0.78), (c,d) day 8.32, and (e,f) day 11.32. Traces for 402.0 and $12.6 \mathrm{~s}$ were superimposed for $(\mathbf{a}, \mathbf{b})$ and $(\mathbf{c}, \mathbf{d})$, respectively. In the images of $(\mathbf{a}-\mathbf{d})$, traces obtained for the last $12.6 \mathrm{~s}$ ( 6 frames $\times 2.09 \mathrm{~s} /$ frame) were superimposed with different colors for visualization purposes. Scale bar in (a) indicates $0.5 \mathrm{~mm}$. 

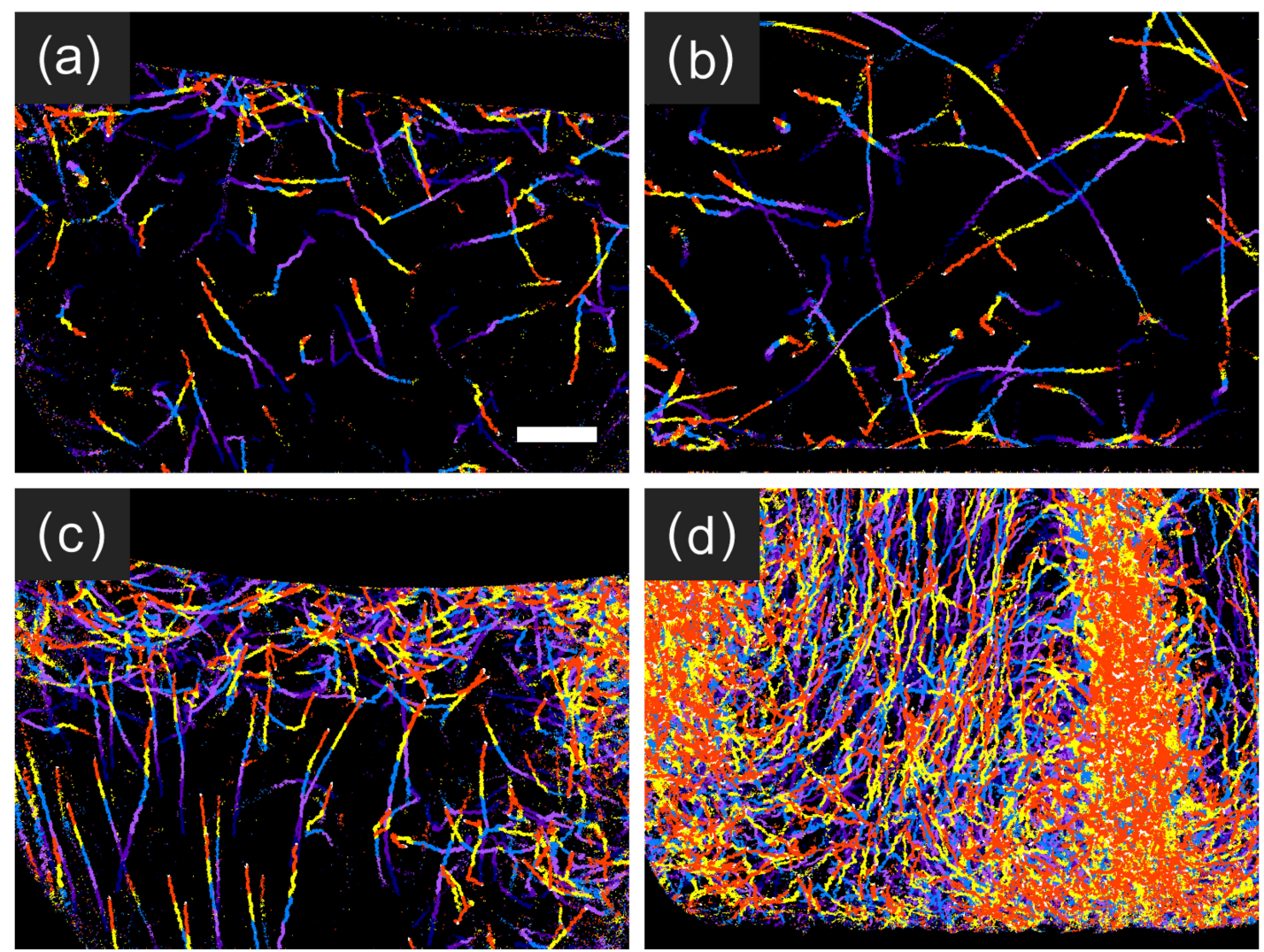

Figure 7. Trace image observed for type C experiment: (a) top area at day 1.00, (b) bottom area at day 0.93, (c) top area at day 4.11 , and (d) bottom area at day 3.78. Black top area in $(\mathbf{a}, \mathbf{c})$ was air at the surface, black bottom area in $(\mathbf{b}, \mathbf{d})$ was the bottom of the type $\mathrm{C}$ chamber, and left bottom black corner in each image was due to the microscope's observation edge. Traces for $12.4 \mathrm{~s}$ ( 6 frames $\times 2.06 \mathrm{~s} /$ frame) were superimposed with different colors for visualization purposes. Scale bar in (a) indicates $0.5 \mathrm{~mm}$.

\section{Discussion}

The main findings of this study are as follows: (1) a specific trend of gravitaxis change in the initially positive gravitactic cells and (2) a high rate of cell multiplication of those cells. Finding (1) revealed that cells transferred to fresh culture medium change their gravitaxis from initially positive to negative, then subsequently to moderate, and finally to negative in synchrony with cell multiplication. Whether those cells originally exhibited positive gravitaxis before transferring to fresh culture medium is not certain; however, it is probable that they exhibited negative gravitaxis before transferring, given that the majority of swimming cells after 4 days of culture showed negative gravitaxis (Figure 6d compared with Figure 6c). Therefore, some cells (ca. 30\% in our experiments) switched from negative to positive gravitaxis upon transfer to fresh culture medium and started the gravitactic transition mentioned above as cell multiplication proceeded.

Finding (2) indicated that transfer to fresh culture medium induced a higher rate of cell multiplication only for those cells that switched their gravitaxis from negative to positive at transfer. This observation implies that cell multiplication is suppressed in cells after prolonged culture and that suppression is released by transfer to fresh culture medium. From findings (1) and (2), we deduced that, when transferred to fresh culture medium, approximately $30 \%$ of E. gracilis cells switch their metabolic status which governs gravitaxis and cell multiplication to initially positive gravitaxis with a high rate of cell multiplication.

Finding (1) also strongly suggests that the gravitaxis of E. gracilis is actively controlled by a previously unidentified flagellar motion and not passively by buoyancy, as imagined from the circular swimming traces $[5,18]$, and some cells were observed to change their gravitaxis upon transfer to fresh culture medium. It appears more likely that the cells 
changed their gravitaxis by the active control of flagellar motion due to sensing a sudden environmental change rather than by changing body weight from stern-heavy to anteriorheavy. In addition, circular swimming traces were found in a few cases of the phototaxis of E. gracilis SM-ZK strain (Supplementary Figure S5). E. gracilis WT cells usually change their swimming direction in an on-site rotation manner by phototaxis, as we previously reported [28-30]. The majority of SM-ZK cells also show on-site rotation in phototaxis, but some cells exhibit circular swimming to turn toward a darker area. Despite rare cases in phototaxis, the observations suggest that $E$. gracilis possesses three modes of flagellar motion: straightforward swimming, on-site rotation, and circular swimming. The preferred mode of change to swimming direction for phototaxis is on-site rotation and, for gravitaxis, circular swimming. Compared with the photosensor in E. gracilis [31-33], the gravity sensor is believed to produce only occasional and weak signals [34,35], which may not be sufficient to induce on-site rotation but enough to induce only circular swimming.

The ecological significance of the change in gravitaxis over the time course of cell multiplication after transferring to fresh culture medium is unclear at present. It may simply be a side effect of switching metabolic status to higher cell multiplication, or it may contribute to survival by increasing diversity. Cell metabolism after transfer to fresh culture medium markedly differs among cells, and the initial gravitaxis appears be a good index to identify cells with a higher rate of multiplication.

\section{Conclusions}

The present study revealed temporal changes in the gravitaxis of E. gracilis cells after transfer to fresh culture medium. Approximately $30 \%$ of the transferred cells showed positive gravitaxis, which subsequently became negative, then moderate, and finally settled as negative. The trend of gravitaxis change was common among cells with initially positive gravitaxis, and such cells exhibited a higher rate of multiplication than those with initially negative gravitaxis. These findings suggest that, following transfer to fresh culture medium, approximately $30 \%$ of $E$. gracilis cells switch their metabolic status, which governs gravitaxis and cell multiplication, to initially positive gravitaxis with a higher rate of multiplication. The circular swimming observed for gravitaxis can be attributed to the active control of the flagella rather than to a passive buoyancy effect. The occurrence of bioconvection was also visualized as a vertical motion of cell mass. Our experimental method using a microchamber with single-cell confinement is an effective means of quantitatively investigating and analyzing gravitaxis and cell multiplication. Moreover, the method enables the visual determination of swimming motion and bioconvection.

Supplementary Materials: The following are available online at https:/ /www.mdpi.com/article/10 .3390 / plants10071411/s1, Figure S1: Initial stage of temporal change of the center of cell distribution $\left(\mathrm{Xc}_{\mathrm{c}} \mathrm{Yc}_{\mathrm{c}}\right.$, swimming activity evaluated as a TM value, and cell number estimated by our analyzing algorithm (initial part of Figure 2). Figure S2: Temporal changes in the center of cell distribution $Y_{c}$ and swimming activity evaluated as a TM value for cases of initially moderate gravitaxis. 14 cases are divided into (a) and (b). Movie S3: Real-time movie of $20 \mathrm{~s}$ at the top surface area in type C experiment at 3.78 day. A large number of cells are sinking down as a bioconvection column at the right side. The scene corresponds to Figure 7c (separate experiment). Movie S4: Real-time movie of $20 \mathrm{~s}$ at the bottom area in type $\mathrm{C}$ experiment at 3.78 day. A downward bioconvection column can be observed at the right side. The scene corresponds to Figure 7d (same experiment). Figure S5: Phototactic motions observed for SM-ZK cells. The microchamber was placed horizontally, and blue light $(465-475 \mathrm{~nm})$ of an intensity of $9.1 \mathrm{~mW} / \mathrm{cm} 2$ was illuminated from the left side. Traces for $7.7 \mathrm{~s}$ ( 6 frames $\times 1.29 \mathrm{~s} /$ frame) were superimposed with different colors for visualization purpose. Scale bar in (a) indicates $0.5 \mathrm{~mm}$.

Author Contributions: This research was planned and overseen by K.O. with the advice of S.S., S.K., T.S., and M.M. The preparation of PDMS microchamber chips was made by H.K. with supervision by S.S. The experiments and data analysis were performed by K.O. All authors reviewed the manuscript. All authors have read and agreed to the published version of the manuscript. 
Funding: This work was supported by a grant for pioneering projects "Fundamental Principles Underlying the Hierarchy of Matter: A Comprehensive Experimental Study", provided by RIKEN. This research was also partially supported by a National Research Foundation of Korea (NRF) grant funded by the Korean government [2012R1A6A1029029 and 2021R1A2B5B03002103]. A part of this work was supported by Japan Society for the Promotion of Science [grant number 17K07945] to Dr T. Shinomura.

Informed Consent Statement: Not applicable.

Acknowledgments: The authors would like to thank Kengo Suzuki and Ayaka Nakashima at Euglena Co. Ltd. (https: / / www.euglena.jp/en/index.html, 7 July 2021) for supplying Euglena gracilis cells and culture medium, together with information on cell culture. The authors appreciate stimulating discussions with Shun Tamaki (RIKEN, previously Teikyo University).

Conflicts of Interest: The authors declare no competing financial interest.

\section{References}

1. Machemer, H.; Bräucker, R. Gravireception and Graviresponses in Ciliates. Acta Protozool. 1992, 31, 185-214. [PubMed]

2. Hemmersbach, R.; Volkmann, D.; Häder, D.-P. Graviorientation in Protists and Plants. J. Plant Physiol. 1999, 154, 1-15. [CrossRef]

3. Braun, M.; Böhmer, M.; Häder, D.-P.; Hemmersbach, R.; Palme, K. Gravitational Biology I: Gravity Sensing and Graviorientation in Microorganisms and Plants; Springer International Publishing: New York, NY, USA, 2018.

4. Lebert, M.; Häder, D.-P. How Euglena Tells Up from Down. Nature 1996, 379, 590. [CrossRef]

5. Richter, P.; Ntefidou, M.; Streb, C.; Lebert, M.; Häder, D.-P. Cellular Perception and Transduction Mechanisms of Gravity in Unicellular Organisms. Curr. Topics Plant Biol. 2002, 3, 143-154.

6. Fukui, K.; Asai, H. Negative Geotactic Behavior of Paramecium Caudatum is Completely Described by the Mechanism of Buoyancy-Oriented Upward Swimming. Biophys. J. 1985, 47, 479-482. [CrossRef]

7. Häder, D.-P.; Hemmersbach, R.; Lebert, M. Gravity and the Behavior of Unicellular Organisms; Cambridge University Press: Cambridge, UK, 2005.

8. Ruangsomboon, S.; Sornchai, P.; Prachom, N. Enhanced Hydrocarbon Production and Improved Biodiesel Qualities of Botryococcus Braunii KMITL 5 by Vitamins Thiamine, Biotin and Cobalamin Supplementation. Algal Res. 2018, 29, 159-169. [CrossRef]

9. Muramatsu, S.; Atsuji, K.; Yamada, K.; Ozasa, K.; Suzuki, H.; Takeuchi, T.; Hashimoto-Marukawa, Y.; Kazama, Y.; Abe, T.; Suzuki, K.; et al. Isolation and Characterization of a Motility-Defective Mutant of Euglena Gracilis. PeerJ Life Environ. 2020, 8, e10002. [CrossRef]

10. Zhou, Y.; Obenour, D.R.; Scavia, D.; Johengen, T.H.; Michalak, A.M. Spatial and Temporal Trends in Lake Erie Hypoxia, 1987-2007. Environ. Sci. Technol. 2013, 47, 899-905. [CrossRef]

11. Jarvie, H.P.; Johnson, L.T.; Sharpley, A.N.; Smith, D.R.; Baker, D.B.; Bruulsema, T.W.; Confesor, R. Increased Soluble Phosphorus Loads to Lake Erie: Unintended Consequences of Conservation Practices? J. Environ. Quality 2017, 46, 123-132. [CrossRef]

12. Buetow, D.E. The biology of Euglena; Academic Press: New York, NY, USA, 1968; Volume 1.

13. Barsanti, L.; Gualtieri, P. Chapter 4-Anatomy of Euglena Gracilis. Handbook of Algal Science, Technology, and Medicine; Academic Press: New York, NY, USA, 2020; Volume 70, pp. 61-70.

14. Stallwitz, E.; Häder, D.-P. Effects of Heavy Metals on Motility and Gravitactic Orientation of the Flagellate, Euglena Gracilis. Eur. J. Protistol. 1994, 30, 18-24. [CrossRef]

15. Lebert, M.; Porst, M.; Häder, D.-P. Circadian Rhythm of Gravitaxis in Euglena Gracilis. J. Plant Physiol. 1999, 155, 344-349. [CrossRef]

16. Häder, D.-P.; Hemmersbach, R. Gravitaxis in Euglena. In Euglena: Biochmistry, Cell and Molecular Biology; Schwartzbach, S.D., Sigeoka, S., Eds.; Springer: Cham, Switzerland, 2017; pp. 237-266.

17. Cramer, M.; Myers, J. Growth and Photosynthetic Characteristics of Euglena Gracilis. Arch. Mikrobiol. 1952, 17, $384-402$. [CrossRef]

18. Ozasa, K.; Won, J.; Song, S.; Shinomura, T.; Maeda, M. Phototaxis and Photo-Shock Responses of Euglena Gracilis under Gravitaxis. Algal Res. 2019, 41, 101563. [CrossRef]

19. Ozasa, K.; Lee, J.; Song, S.; Hara, M.; Maeda, M. Two-Dimensional Optical Feedback Control of Euglena Confined in Closed-Type Microfluidic Channels. LabChip 2011, 11, 1933-1940. [CrossRef]

20. Ozasa, K.; Lee, J.; Song, S.; Hara, M.; Maeda, M. Gas/Liquid Sensing via Chemotaxis of Euglena Cells Confined in an Isolated Micro-Aquarium. LabChip 2013, 13, 4033-4039. [CrossRef] [PubMed]

21. Ozasa, K.; Lee, J.; Song, S.; Maeda, M. Real-Time Analysis of Chemotactic Motion of Euglena Cells Confined in a Microchip Toxicity Sensor. Key Eng. Mater. 2015, 644, 185-188.

22. Gillott, M.A.; Triemer, R.E. The Ultrastructure of Cell Division in Euglena Gracilis. J. Cell Sci. 1978, 31, 25-35. [CrossRef] [PubMed]

23. Habib, G.M.; Bouck, B.G. Synthesis and Mobilization of Flagellar Glycoprotein during Regeneration in Euglena. J. Cell Biol. 1982, 93, 432-441. [CrossRef]

24. Okuwa-Hayashi, H.; Inui, H.; Inagaki, J.; Nakazawa, M.; Ebara, S.; Sakamoto, T.; Nakano, Y. Effect of Nicotinamide on the Flagellar Detachment and Regeneration of Euglena. Vitam. Japan 2019, 93, 115-122. 
25. Hill, N.A.; Pedley, T.J. Bioconvection. Fluid Dyn. Res. 2005, 37, 1-20. [CrossRef]

26. Bearon, R.N.; Grünbaum, D. Bioconvection in a Stratified Environment: Experiments and Theory. Phys. Fluids 2006, 18, 127102. [CrossRef]

27. Bees, M.A. Advances in Bioconvection. Ann. Rev. Fluid Mechan. 2020, 52, 449-476. [CrossRef]

28. Ozasa, K.; Lee, J.; Song, S.; Maeda, M. Transient Freezing Behavior in Photophobic Responses of Euglena Gracilis Investigated in a Microfluidic Device. Plant Cell Physiol. 2014, 55, 1704-1712. [CrossRef]

29. Kato, S.; Ozasa, K.; Maeda, M.; Tanno, Y.; Tamaki, S.; Higuchi-Takeuchi, M.; Numata, K.; Kodama, Y.; Sato, M.; Toyooka, K.; et al. Carotenoids are Essential for Light Perception by the Eyespot Apparatus to Initiate the Phototactic Movement of Euglena Gracilis. Plant J. 2020, 101, 1091-1102. [CrossRef] [PubMed]

30. Tamaki, S.; Tanno, Y.; Kato, S.; Ozasa, K.; Wakazaki, M.; Sato, M.; Toyooka, K.; Maoka, T.; Ishikawa, T.; Maeda, M.; et al. Carotenoid Accumulation in the Eyespot Apparatus Required for Phototaxis is Independent of Chloroplast Development in Euglena Gracilis. Plant Sci. 2020, 298, 110564. [CrossRef]

31. Iseki, M.; Matsunaga, S.; Murakami, A.; Ohno, K.; Shiga, K.; Yoshida, K.; Sugai, M.; Takahashi, T.; Hori, T.; Watanabe, M. A Blue-Light Activated Adenylyl Cyclase Mediates Photoavoidance in Euglena gracilis. Nature 2002, 415, 1047-1051. [CrossRef] [PubMed]

32. Yoshikawa, S.; Suzuki, T.; Watanabe, M.; Iseki, M. Kinetic Analysis of the Activation of Photoactivated Adenylyl Cyclase (PAC), a Blue-Light Receptor for Photomovements of Euglena. Photochem. Photobiol. Sci. 2005, 4, 727-731. [CrossRef]

33. Häder, D.-P.; Iseki, M. Photomovement in Euglena. In Euglena: Biochmistry, Cell and Molecular Biology; Schwartzbach, S.D., Shigeoka, S., Eds.; Springer: Berlin, Germany, 2017; pp. 207-235.

34. Häder, D.-P.; Richter, P.R.; Schuster, M.; Daiker, V.; Lebert, M. Molecular Analysis of the Graviperception Signal Transduction in the Flagellate Euglena Gracilis: Involvement of a Transient Receptor Potential-Like Channel and a Calmodulin. Adv. Space Res. 2009, 43, 1179-1184. [CrossRef]

35. Nasir, A.; Bail, A.L.; Daiker, V.; Klima, J.; Richter, P.; Lebert, M. Identification of a Flagellar Protein Implicated in the Gravitaxis in the Flagellate Euglena Gracilis. Sci. Rep. 2018, 8, 7605. [CrossRef] 